\title{
Clinical characterization of patients with primary aldosteronism plus subclinical Cushing's syndrome
}

Shigemitsu Yasuda ${ }^{1 *} \mathbb{D}$, Yusuke Hikima', Yusuke Kabeya ${ }^{2}$, Shinichiro lida ${ }^{1}$, Yoichi Oikawa', Masashi Isshiki ${ }^{1}$, Ikuo Inoue ${ }^{1}$, Akira Shimada ${ }^{1}$ and Mitsuhiko Noda ${ }^{1,3}$

\begin{abstract}
Background: Primary aldosteronism (PA) plus subclinical Cushing's syndrome (SCS), PASCS, has occasionally been reported. We aimed to clinically characterize patients with PASCS who are poorly profiled.

Methods: A population-based, retrospective, single-center, observational study was conducted in 71 patients (age, $58.2 \pm 11.2$ years; 24 males and 47 females) who developed PA $(n=45)$, SCS $(n=12)$, or PASCS $(n=14)$. The main outcome measures were the proportion of patients with diabetes mellitus (DM), serum potassium concentration, and maximum tumor diameter (MTD) on the computed tomography (CT) scans.

Results: The proportion of DM patients was significantly greater in the PASCS group than in the PA group (50.0\% vs. $13.9 \%, p<0.05)$, without a significant difference between the PASCS and SCS groups. Serum potassium concentration was significantly lower in the PASCS group than in the SCS group $(3.2 \pm 0.8 \mathrm{mEq} / \mathrm{L}$ vs. $4.0 \pm 0.5 \mathrm{mEq} / \mathrm{L}$; $p<0.01$ ), without a significant difference between the PASCS and PA groups. Among the 3 study groups of patients who had a unilateral adrenal tumor, MTD was significantly greater in the PASCS group than in the PA group ( $2.7 \pm 0.1 \mathrm{~cm}$ vs. $1.4 \pm 0.1 \mathrm{~cm} ; p<0.001)$, without a significant difference between the PASCS and SCS groups.

Conclusions: Any reference criteria were not obtained that surely distinguish patients with PASCS from those with PA or SCS. However, clinicians should suspect the presence of concurrent SCS in patients with PA when detecting a relatively large adrenal tumor on the $\mathrm{CT}$ scans.
\end{abstract}

Keywords: Primary aldosteronism, Subclinical Cushing's syndrome, Adrenal tumor, Maximum tumor diameter, Diabetes mellitus, Serum potassium

\section{Background}

Primary aldosteronism (PA), an adrenocortical disorder caused by an adrenal tumor that overproduces aldosterone, accounts for 5 to $15 \%$ of patients with hypertension [1]. Cushing's syndrome (CS), an endocrinopathy resulting from the prolonged, excessive adrenocortical secretion of cortisol, falls roughly into the following 2 categories: adrenocorticotropic hormone (ACTH)-dependent CS and ACTH-independent CS; the former includes Cushing's disease that is primarily caused by a pituitary ACTHsecreting tumor and ectopic ACTH syndrome resulting

\footnotetext{
* Correspondence: syasuda@saitama-med.ac.jp

${ }^{1}$ Department of Endocrinology and Diabetes, Saitama Medical University,

Morohongo 38, Moroyama, Iruma-gun, Saitama 350-0495, Japan

Full list of author information is available at the end of the article
}

from extrapituitary ACTH-secreting tumors (eg, bronchial carcinoid) [2], while the latter is usually caused by unilateral adenomas or carcinomas that provoke the autonomous adrenal cortical secretion [3]. Subclinical Cushing's syndrome (SCS), an ill-defined endocrine disorder leading to the ACTH-independent secretion of cortisol from an adrenal adenoma that is not fully restrained by pituitary feedback [4], is known to cause hypertension, glucose intolerance, and dyslipidemia [5].

The concurrence of clinically overt hyperaldosteronism and subclinical hypercortisolism is rare in PA patients [6]. To date, a few number of studies have examined the clinicopathological features of patients with PA plus SCS (PASCS), the incidences of which have ranged between about 10 and $20 \%$ [7, 8]. Lower plasma

(c) The Author(s). 2020 Open Access This article is distributed under the terms of the Creative Commons Attribution 4.0 International License (http://creativecommons.org/licenses/by/4.0/), which permits unrestricted use, distribution, and reproduction in any medium, provided you give appropriate credit to the original author(s) and the source, provide a link to the Creative Commons license, and indicate if changes were made. The Creative Commons Public Domain Dedication waiver (http://creativecommons.org/publicdomain/zero/1.0/) applies to the data made available in this article, unless otherwise stated. 
ACTH levels and a greater tumor size were found in patients with PASCS than in patients with PA alone [8]. In the clinical settings, we rarely encounter PASCS patients who show a small adrenal tumor on the computed tomography (CT) scans and/or do not have a low plasma ACTH level in blood samples collected in the early morning. To examine the clinical features of PASCS patients in the present study, we compared clinical, laboratory, and imaging characteristics among patients with PA, SCS, or PASCS.

\section{Methods}

\section{Patients}

We conducted a population-based, retrospective, singlecenter, observational study in 187 patients (119 with PA, 54 with SCS, and 14 with PASCS) at Saitama Medical University Hospital, Saitama, Japan, between January 1999 and December 2016. Hypertensive patients with suspected PA or SCS, as well as normotensive or hypertensive patients with an adrenal incidentaloma were referred to our hospital. A total of 116 patients were excluded from the study: 31 who were diagnosed with PA or SCS only because tests required to definitely diagnose these endocrinopathies were not conducted; 61 who failed to meet the new Japanese diagnostic criteria of SCS [9]; 1 who failed to meet the new Korean diagnostic criteria of subclinical hypercortisolism [10]; and 23 who failed to meet the Japanese [11] and United States [12] diagnostic criteria of PA. Therefore, we investigated 71 patients who were definitely diagnosed with PA and/or SCS (45 with PA, 12 with SCS, and 14 with PASCS). This study was approved by the institutional review board of Saitama Medical University. Patients provided written informed consent to the use of their clinical and laboratory data in the study.

\section{Diagnosis of PA and SCS}

Hormones required for the diagnosis of PA and SCS were assayed according to the procedures described in the pertinent guidelines $[9,11]$. Serum cortisol and plasma ACTH levels were determined by electrochemiluminescence immunoassay, plasma aldosterone concentration (PAC) and plasma renin activity (PRA) by radioimmunoassay, and serum dehydroepiandrosterone sulfate (DHEAS) level by chemiluminescent enzyme immunoassay (SRL Inc., Tokyo, Japan). Blood samples were collected in the early morning (7 a.m. to 9 a.m.). PA was suspected when detecting elevated PAC $(\geq 150 \mathrm{pg} / \mathrm{mL})$, low PRA $(\leq 1.0 \mathrm{ng} / \mathrm{mL} / \mathrm{hr})$, and/or the elevated aldosterone-to-renin ratio $(>200)$. We conducted the following 3 challenge tests in accordance with the Japanese guidelines of PA [11]: captopril challenge test, furosemide upright posture challenge test, and ACTH challenge test. PA was diagnosed when at least 1 of these 3 challenge tests afforded results compatible with the disease. Furthermore, we also referred to the American guideline of PA [12] for selecting only patients who met the diagnostic criteria for
PA. Prior to the confirmatory tests, patients had not received any antihypertensive drugs for at least 2 weeks except for those with severe hypertension treated with calcium-channel blockers and/or $\alpha$-blockers. Adrenal venous sampling (AVS), whose usefulness was well documented in the Japanese and United States guidelines [11-13], was conducted in all of patients who had PA or PASCS to make the differential diagnosis of uni- or bilateral aldosterone hypersecretion.

The low-dose (1-mg) dexamethasone suppression test (DST) and the corticotropin-releasing hormone (CRH) challenge test were conducted, and the diurnal rhythms of cortisol were also determined-all for the diagnosis of SCS. Moreover, the high-dose (8-mg) DST was also conducted to rule out ACTH-dependent CS. Test results were assessed in accordance with the diagnostic criteria advocated by the Japan Endocrine Society [9] to make the definite diagnosis of SCS. Concretely, patients were required to meet the requisites 1-3)-1) presence of an adrenal incidentaloma; 2) lack of characteristic features of Cushing's syndrome; and 3) normal basal serum cortisol levels, as well as to have either of the requisites 4-6) -4) the cutoff value of serum cortisol level for the diagnosis of SCS was $\geq 5 \mu \mathrm{g} / \mathrm{dL}$ after the $1-\mathrm{mg}$ DST, 5) the cutoff value of serum cortisol level for the diagnosis of SCS was $\geq 3 \mu \mathrm{g} / \mathrm{dL}$ after the 1-mg DST, and at least 1 of "Low plasma levels of ACTH in the early morning," "No diurnal changes in serum cortisol levels," "Unilateral uptake on adrenal scintigraphy," "Low serum levels of DHEAS," or the presence of "Transient adrenal insufficiency or atrophy of the attached normal adrenal cortex after removal of the adrenal tumor," or 6) the cutoff value of serum cortisol level for the diagnosis of SCS was $\geq 1.8 \mu \mathrm{g} / \mathrm{dL}$ after the $1-\mathrm{mg}$ DST, with the presence of "Low plasma levels of ACTH in the early morning" and "No diurnal changes in serum cortisol levels," or the presence of "Transient adrenal insufficiency or atrophy of the attached normal adrenal cortex after removal of the adrenal tumor." In the present study, we examined only patients who met the requisites $1-3$ ) and either 1 of the requisites 4-6) as patients with SCS. All patients underwent 128-slice CT of the adrenal glands. ${ }^{131}$ I-adosterol adrenal scintigraphy was conducted in all of patients who had SCS or PASCS to specify the laterality of the adrenal tumor. Consequently, 7 of 12 patients with SCS and 8 of 14 patients with PASCS underwent adrenalectomy. Postsurgical histopathological examination confirmed cortisol hypersecretion based on the atrophy of the normal area adjacent to the adenoma of the removed adrenal gland [9].

\section{Study outcome measures}

At the initial visit, all patients were checked up for their age and sex. Systolic blood pressure (SBP), diastolic blood pressure (DBP), and the outcome measures listed in Table 1 were examined in untreated patients. At the time of admission to the hospital for making the definite diagnosis, height and body weight were measured to 
calculate body mass index (BMI). In the early morning of the next day of admission to the hospital, blood pressures were measured. Blood samples were collected to determine PAC, PRA, as well as plasma ACTH, serum cortisol, and serum DHEAS levels. The laterality of the adrenal tumor was confirmed based on the results from AVS and/or CT. The Hounsfield number and MTD of adrenal tumors were determined on the CT scans.

The following terms were defined for PASCS: hypertension, $\mathrm{SBP} \geq 140 \mathrm{mmHg}$ and/or $\mathrm{DBP} \geq 90 \mathrm{mmHg}$ [14]; diabetes mellitus (DM), an fasting plasma glucose (FPG) level $\geq 126 \mathrm{mg} / \mathrm{dL}$, a 2 -h plasma glucose level $\geq 200 \mathrm{mg} /$ $\mathrm{dL}$ in the $75-\mathrm{g}$ oral glucose tolerance test, and/or a serum hemoglobin A1c (HbA1c) level $\geq 6.5 \%$ in national glycohemoglobin standardization program [15]; and dyslipidemia, a serum triglyceride (TG) level $\geq 150 \mathrm{mg} / \mathrm{dL}$, a serum high-density lipoprotein cholesterol (HDL-C) level $<40 \mathrm{mg} / \mathrm{dL}$, or a serum low-density lipoprotein cholesterol (LDL-C) level $\geq 140 \mathrm{mg} / \mathrm{dL}$ [16]. To specify the source of aldosterone hypersecretion by AVS, the following diagnostic criteria were used: 1) the laterality ratio (LR) and the contralaterality ratio (CR) calculated before and after the ACTH challenge test in reference to the Japanese guidelines of PA [11]; 2) the absolute PAC value of $\geq 14,000 \mathrm{pg} / \mathrm{mL}$ in reference to the articles of Ohmura [17] and Makita [18]; and 3) the aldosterone ratio of the right and left adrenal veins. According to the Japanese guidelines of PA [11], an LR of $>4$ and a CR of $<1$ after the ACTH challenge test were used as the cutoff values. Tumor laterality was determined based on a CR of $<1$ and the absolute PAC value of $\geq 14,000 \mathrm{pg} / \mathrm{mL}$ when the ACTH challenge test indicated an LR of 2 to 4 or a discrepancy occurred in tumor laterality before and after the ACTH challenge test. Since serum cortisol levels considerably differed in the adrenal veins of PASCS patients, the adrenal gland secreting cortisol predominantly was determined based on the aldosterone ratio and on the right-to-left ratio of aldosterone and cortisol in the adrenal veins in reference to the article of Hiraishi et al. [8]. Moreover, tumor laterality was determined based on the results from ${ }^{131} \mathrm{I}$-adosterol adrenal scintigraphy and on the absolute value of PAC in reference to the articles of Funder et al. [12] and Minami et al. [13]. We did not measure plasma metanephrine concentrations, although the measurement thereof is useful for determining the need for AVS [19] in patients with the suspected concurrence of aldosterone and cortisol hypersecretion.

\section{Statistical analyses}

Continuous and categorical variables were analyzed according to the one-way analysis of variance and Fisher's exact test, respectively. Two of the 3 study groups were analyzed according to Student's t-test. Bonferroni's correction was applied to the $p$ values from Student's ttest or Fisher's exact test in multiple comparisons between 2 among the 3 study groups. Blood steroid profiles were compared between 2 groups according to Student's t-test or the Mann-Whitney U-test.

In addition, the multiple linear regression analysis adjusted for age, sex, and BMI was performed to examine differences in MTD and serum potassium concentration among the PA, SCS, and PASCS groups. MTD was not measured in 1 of 42 patients in the PA group who had a unilateral adrenal tumor. Therefore, the data from the patient were excluded as the missing data.

A value of $p<0.05$ was considered statistically significant. The JMP software version 9.0 (SAS Institute, Cary, $\mathrm{NC}$, USA) was used to make all statistical analyses except multiple linear regression analysis that was performed using the STATA software version 14 (Stata Corp, College Station, TX, USA).

\section{Results \\ Study population}

The clinical, laboratory, and imaging characteristics of 71 patients are shown in Table 1. Mean age was $58.2 \pm 11.2$ years, females $(n=47,66.2 \%)$ were predominant, and mean BMI was $25.2 \pm 4.5 \mathrm{~kg} / \mathrm{m}^{2}$. No significant difference was found in age, sex, and BMI among the PA, SCS, and PASCS groups (Table 1). SBP and DBP of patients with untreated hypertension were $165.6 \pm 26.1 \mathrm{mmHg}$ and $96.0 \pm 13.6 \mathrm{mmHg}$, respectively, in the PA group in contrast to $145.6 \pm 26.9 \mathrm{mmHg}$ and $80.0 \pm 12.7 \mathrm{mmHg}$, respectively, in the SCS groups. DBP was significantly greater $(p<0.01)$ in the PA group than in the SCS group.

Comorbidities are shown in Table 1. Hypertension occurred in 45 (100\%), 9 (75.0\%), and 13 (92.9\%) patients in the PA, SCS, and PASCS groups, respectively. The proportion of patients with hypertension was significantly greater $(p<0.05)$ in the PA group than in the SCS group; however, no significant difference was found between the PASCS group and the PA group. Notably, the incidence of hypertension was $100 \%$ in patients with PA. DM occurred in 6 (14.0\%), 6 (50.0\%), and 7 (50.0\%) patients in the PA, SCS, and PASCS groups, respectively. The proportion of DM patients was significantly greater $(p<0.05)$ in the PASCS group than in the PA group. Dyslipidemia occurred in 25 (56.8\%), 10 (83.3\%), and 9 (64.3\%) patients in the PA, SCS, and PASCS groups, respectively; however, no significant difference was found among these study groups.

Results from laboratory tests are shown in Table 1. FPG was greater not statistically but numerically in the PASCS group than in the PA group $(131.6 \pm 52.1 \mathrm{mg} / \mathrm{dL}$ vs. $103.8 \pm 28.5 \mathrm{mg} / \mathrm{dL} ; p=0.09)$. On the other hand, FPG was statistically greater in the SCS group than in the PA group $(150.0 \pm 60.7 \mathrm{mg} / \mathrm{dL}$ vs. $103.8 \pm 28.5 \mathrm{mg} /$ 
Table 1 Clinical, laboratory, and imaging characteristics of untreated patients with PA, SCS, or PASCS

\begin{tabular}{|c|c|c|c|c|c|c|c|}
\hline & \multicolumn{3}{|c|}{ Study diseases } & \multicolumn{4}{|c|}{$P$ values in between-group comparisons } \\
\hline & $\begin{array}{l}\mathrm{PA} \\
(\mathrm{n}=45)\end{array}$ & $\begin{array}{l}\text { SCS } \\
(n=12)\end{array}$ & $\begin{array}{l}\text { PASCS }^{a} \\
(n=14)\end{array}$ & $\overline{A l l}{ }^{\mathrm{b}}$ & PA vs. PASCS & SCS vs. PASCS & PA vs. SCS \\
\hline \multicolumn{8}{|l|}{ Clinical characteristics } \\
\hline Age, y & $56.2 \pm 1.0$ & $62.5 \pm 12.6$ & $60.8 \pm 13.1$ & NS & & & \\
\hline Sex, female, n (\%) & $29(64.4)$ & $7(58.3)$ & $11(78.6)$ & NS & & & \\
\hline $\mathrm{BMI}, \mathrm{kg} / \mathrm{m}^{2}$ & $24.9 \pm 4.2$ & $25.2 \pm 5.9$ & $26.0 \pm 4.4$ & NS & & & \\
\hline $\mathrm{SBP}, \mathrm{mmHg}$ & $165.6 \pm 26.1$ & $145.6 \pm 26.9$ & $150.1 \pm 27.2$ & $<0.05$ & NS & NS & NS \\
\hline $\mathrm{DBP}, \mathrm{mmHg}$ & $96.0 \pm 13.6$ & $80.0 \pm 12.7$ & $90.5 \pm 16.4$ & $<0.01$ & NS & NS & $<0.01$ \\
\hline \multicolumn{8}{|l|}{ Comorbidities } \\
\hline Hypertension, n (\%) & $45(100.0)$ & $9(75.0)$ & $13(92.9)$ & $<0.01$ & NS & NS & $<0.05$ \\
\hline Diabetes mellitus, n (\%) & $6(14.0)$ & $6(50.0)$ & $7(50.0)$ & $<0.01$ & $<0.05$ & NS & NS \\
\hline Dyslipidemia, n (\%) & $25(56.8)$ & $10(83.3)$ & $9(64.3)$ & NS & & & \\
\hline \multicolumn{8}{|l|}{ Laboratory characteristics } \\
\hline $\mathrm{FPG}, \mathrm{mg} / \mathrm{dL}$ & $103.8 \pm 28.5$ & $150.0 \pm 60.7$ & $131.6 \pm 52.1$ & $<0.005$ & NS & NS & $<0.01$ \\
\hline $\mathrm{HbA1c}$ NGSP, \% & $5.7 \pm 0.9$ & $7.3 \pm 2.2$ & $6.5 \pm 2.1$ & $<0.01$ & NS & NS & $<0.01$ \\
\hline $\mathrm{TC}, \mathrm{mg} / \mathrm{dL}$ & $197.5 \pm 42.5$ & $208.1 \pm 54.7$ & $195.1 \pm 30.4$ & NS & & & \\
\hline $\mathrm{TG}, \mathrm{mg} / \mathrm{dL}$ & $131.7 \pm 88.2$ & $148.3 \pm 52.9$ & $141.3 \pm 70.3$ & NS & & & \\
\hline $\mathrm{HDL}-\mathrm{C}, \mathrm{mg} / \mathrm{dL}$ & $55.2 \pm 15.3$ & $53.6 \pm 13.9$ & $57.0 \pm 12.4$ & NS & & & \\
\hline $\mathrm{LDL}-\mathrm{C}, \mathrm{mg} / \mathrm{dL}$ & $117.6 \pm 40.3$ & $127.2 \pm 47.5$ & $112.9 \pm 23.6$ & NS & & & \\
\hline Serum potassium, mEq/L & $3.3 \pm 0.7$ & $4.0 \pm 0.5$ & $3.2 \pm 0.8$ & $<0.01$ & NS & $<0.01$ & $<0.01$ \\
\hline Serum calcium, mg/dL & $9.4 \pm 0.4$ & $9.5 \pm 0.4$ & $9.6 \pm 0.4$ & NS & & & \\
\hline Serum phosphorus, mg/dL & $3.5 \pm 0.5$ & $3.3 \pm 0.9$ & $3.3 \pm 0.4$ & NS & & & \\
\hline$\cup A, m g / d L$ & $5.1 \pm 1.1$ & $4.9 \pm 1.1$ & $5.3 \pm 1.3$ & NS & & & \\
\hline Serum ALP, U/L & $212.3 \pm 46.3$ & $256.8 \pm 70.0$ & $279.1 \pm 105.4$ & $<0.005$ & $<0.01$ & NS & NS \\
\hline Erythrocyte, $10^{6} / \mu \mathrm{L}$ & $4.4 \pm 0.5$ & $4.5 \pm 0.7$ & $4.5 \pm 0.3$ & NS & & & \\
\hline Hemoglobin, g/dL & $13.2 \pm 1.6$ & $13.7 \pm 2.0$ & $13.2 \pm 1.4$ & NS & & & \\
\hline Hematocrit, \% & $39.0 \pm 4.1$ & $41.3 \pm 5.5$ & $39.2 \pm 4.1$ & NS & & & \\
\hline Leukocyte, $10^{3} / \mu \mathrm{L}$ & $5.8 \pm 1.6$ & $6.6 \pm 1.3$ & $5.7 \pm 2.0$ & NS & & & \\
\hline Neutrophil, \% & $61.7 \pm 7.2$ & $64.7 \pm 12.7$ & $63.7 \pm 5.3$ & NS & & & \\
\hline Lymphocyte, \% & $28.9 \pm 6.8$ & $27.2 \pm 11.4$ & $28.0 \pm 6.2$ & NS & & & \\
\hline Eosinocyte, \% & $3.9 \pm 3.4$ & $2.4 \pm 2.1$ & $2.4 \pm 1.4$ & NS & & & \\
\hline \multicolumn{8}{|l|}{ Imaging characteristics } \\
\hline \multicolumn{8}{|l|}{ Laterality of tumor ${ }^{d}$} \\
\hline Left-sided, n (\%) & $28(62.2)$ & $9(75.0)$ & $7(50.0)$ & & & & \\
\hline Right-sided, n (\%) & $14(31.1)$ & $3(25.0)$ & $5(35.7)$ & & & & \\
\hline Bilateral, n (\%) & $3(6.7)$ & $0(0.0)$ & $2(14.3)$ & & & & \\
\hline
\end{tabular}

Values are expressed as mean \pm SD or count (\%)

PA primary aldosteronism, SCS subclinical Cushing's syndrome, PASCS primary aldosteronism plus subclinical Cushing's syndrome, BMI body mass index, SBP systolic blood pressure, DBP diastolic blood pressure, $F P G$ fasting plasma glucose, $H b A_{1 c}$ hemoglobin $A_{1 c}, N G S P$ national glycohemoglobin standardization program, TC total cholesterol, TG triglyceride, HDL-C high-density lipoprotein cholesterol, LDL-C low-density lipoprotein cholesterol, UA uric acid, ALP alkaline phosphatase, NS not significant, SD standard deviation

aPatients with primary aldosteronism plus subclinical Cushing's syndrome

${ }^{\mathrm{b}}$ Analyzed according to the one-way analysis of variance

'Bonferroni's correction was applied to the $p$ values from Student's t-test or Fisher's exact test in multiple comparisons between two groups

${ }^{\mathrm{d}}$ Determined by computed tomography, adrenal venous sampling, and ${ }^{131} \mathrm{l}$-adosterol adrenal scintigraphy

A value of $p<0.05$ was considered statistically significant 
$\mathrm{dL} ; p<0.01)$. HbA1c was greater not statistically but numerically in the PASCS group than in the PA group $(6.5 \pm 2.1 \%$ vs. $5.7 \pm 0.9 \% ; p=0.21)$. On the other hand, HbA1c was significantly greater in the SCS group than in the PA group $(7.3 \pm 2.2 \%$ vs. $5.7 \pm 0.9 \%$; $p<0.01)$. Serum potassium concentration was significantly lower in the PA group than in the SCS group $(3.3 \pm 0.7 \mathrm{mEq} / \mathrm{L}$ vs. $4.0 \pm 0.5$ $\mathrm{mEq} / \mathrm{L} ; p<0.01)$ and in the PASCS group than in the SCS group $(3.2 \pm 0.8 \mathrm{mEq} / \mathrm{L}$ vs. $4.0 \pm 0.5 \mathrm{mEq} / \mathrm{L} ; p<0.01)$. No significant difference was found in serum potassium concentration between the PA group and the PASCS group. Serum alkaline phosphatase (ALP) level was significantly greater in the PASCS group than in the PA group $(279.1 \pm 105.4 \mathrm{U} / \mathrm{L}$ vs. $212.3 \pm 46.3 \mathrm{U} / \mathrm{L} ; p<0.01)$. No significant difference was found in serum ALP level between the SCS group and the PASCS group.

Subsequently, differences in CT Hounsfield units and MTD of adrenal tumors among the 3 study groups were examined with respect to 65 patients who had a unilateral adrenal tumor (Table 2). MTD on the CT scans was significantly greater in the PASCS group than in the PA group $(2.7 \pm 0.1 \mathrm{~cm}$ vs. $1.3 \pm 0.1 \mathrm{~cm} ; p<0.001)$ and was also greater in the SCS group than in the PA group $(2.7 \pm 0.2 \mathrm{~cm}$ vs. $1.3 \pm 0.1 \mathrm{~cm} ; p<0.001)$. No significant difference was found in MTD between the SCS group and the PASCS group. MTD was significantly smaller in the PA group than in the other 2 groups, was second smallest in the SCS group, and was largest in the PASCS group (Table 2). MTD ranged as follows: 0.3$2.2 \mathrm{~cm}, 1.8-3.5 \mathrm{~cm}$, and $1.1-5.0 \mathrm{~cm}$ in the PA, SCS, and PASCS groups, respectively (Fig. 1).

The blood steroid profiles of patients with PA or PASCS are shown in Table 3. PAC was significantly greater in the PASCS group than in the PA group (255.0 [713.3-153.5] vs. 208.0 [273.0-159.8]; $p<0.005)$. No significant difference was found in PRA in the morning, while the PAC/PRA ratio was significantly greater in the PASCS group than in the PA group (1450.0 [5010.0529.4] vs. 1258.3 [1956.3-643.1]; $p<0.005)$. The PAC/ PRA ratio in the captopril challenge test was significantly greater in the PASCS group than in the PA group $(3028.5 \pm 3648.9$ vs. $730.7 \pm 745.7 ; p<0.001)$ as with PAC in the captopril challenge test $(348.6 \pm 340.1$ vs. $149.0 \pm 94.2 ; p<0.005)$. Serum cortisol level was significantly greater in the PASCS group than in the PA group $(16.4 \pm 6.6 \mu \mathrm{g} / \mathrm{dL}$ vs. $12.4 \pm 4.3 \mu \mathrm{g} / \mathrm{dL} ; p<0.05)$. The mean serum cortisol level was $17.8 \pm 5.9 \mu \mathrm{g} / \mathrm{dL}$ in the SCS group and was not significantly greater in the SCS group than in the PASCS group $(17.8 \pm 5.9 \mu \mathrm{g} / \mathrm{dL}$ vs. $16.4 \pm 6.6 \mu \mathrm{g} / \mathrm{dL} ; p=0.49)$. No significant difference was found in plasma ACTH and serum DHEAS levels in the early morning; however, these variables were not significantly lower in the PASCS than in the PA group ( $p=$ 0.29 for $\mathrm{ACTH}$ and $p=0.40$ for DHEAS). On the other hand, the peak plasma ACTH levels in the CRH challenge test were significantly lower in the PASCS group than in the PA group $(18.9 \pm 8.9$ vs. $57.1 \pm 10.8$; $p<0.005$ ) (Table 3 ) and were not significantly greater in the SCS group than in the PASCS group $(15.3 \pm 5.6 \mu \mathrm{g} /$ dL vs. $18.9 \pm 8.9 \mu \mathrm{g} / \mathrm{dL} ; p=0.64)$.

\section{Multiple linear regression analysis on MTD and serum potassium concentration with respect to patients in the PA, SCS, and PASCS groups who had a unilateral adrenal tumor}

MTD was significantly greater in the PASCS and SCS groups than in the PA group with respect to patients who had a unilateral adrenal tumor (Table 2). Therefore, we conducted a multiple linear regression analysis adjusted for age, sex, and BMI to examine differences in MTD among the PA, SCS, and PASCS groups. Consequently, MTD was significantly smaller in the PA group than in the PASCS group (difference, $-1.19 \mathrm{~cm} ; 95 \% \mathrm{CI}$,

Table 2 Maximum tumor diameters and computed tomography Hounsfield units of adrenal tumors in patients who had a unilateral adrenal tumor

\begin{tabular}{|c|c|c|c|c|c|c|c|}
\hline & \multicolumn{3}{|c|}{ Study groups } & \multicolumn{4}{|c|}{$P$ values of between-group comparisons } \\
\hline & $\begin{array}{l}\text { PA } \\
\left(n=41^{a}\right)\end{array}$ & $\begin{array}{l}\text { SCS } \\
(n=12)\end{array}$ & $\begin{array}{l}\text { PASCS } \\
\left(n=12^{\mathrm{c}}\right)\end{array}$ & $\overline{A^{\prime}}{ }^{d}$ & $\begin{array}{l}\text { PA vs. } \\
\text { PASCS }\end{array}$ & SCS vs. PASCS & PA vs. SCS \\
\hline \multicolumn{8}{|l|}{ Image characteristics } \\
\hline MTD, cm & $1.3 \pm 0.1$ & $2.7 \pm 0.2$ & $2.7 \pm 0.1$ & $<0.0001$ & $<0.001$ & NS & $<0.001$ \\
\hline Hounsfield number, $\mathrm{HU}$ & $2.5 \pm 19.3$ & $9.2 \pm 19.8$ & $11.3 \pm 6.6$ & NS & & & \\
\hline
\end{tabular}

Values are expressed as mean \pm SD or count (\%)

CT computed tomography, PA primary aldosteronism, SC subclinical Cushing's syndrome, PASCS primary aldosteronism plus subclinical Cushing's syndrome, MTD maximum tumor diameter, $H U$ Hounsfield unit, $S D$ standard deviation, NS not significant, SD standard deviation

${ }^{a}$ The numbers of patients who remained after the exclusion of the following patients who missed the maximum tumor diameter: 1 patient who had a unilateral adrenal tumor and 3 patients who had bilateral adrenal tumors

${ }^{b}$ Patients with primary aldosteronism plus subclinical Cushing's syndrome

'The numbers of patients who remained after the exclusion of 2 patients who had bilateral tumors and who missed the maximum tumor diameter

${ }^{\mathrm{d}}$ Analyzed according to the one-way analysis of variance

'Bonferroni's correction was applied to the $p$ values from Student's t-test or Fisher's exact test in multiple comparisons between two groups

A value of $p<0.05$ was considered statistically significant 


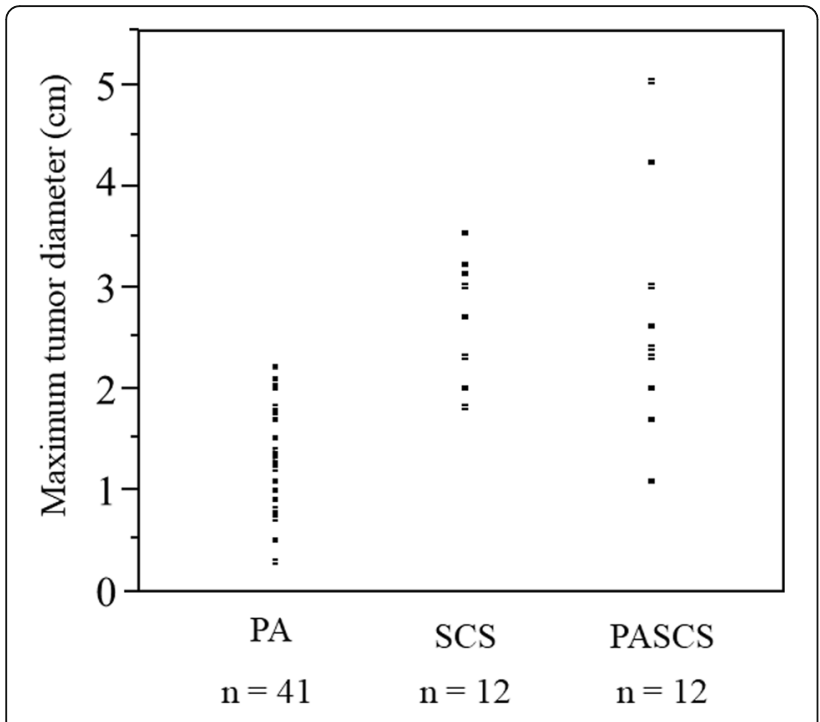

Fig. 1 Maximum tumor diameters in patients with PA, SCS, or PASCS who had a unilateral adrenal tumor. PA, primary aldosteronism; SCS, subclinical Cushing's syndrome, PASCS, primary aldosteronism plus subclinical Cushing's syndrome

-1.66 to $-0.72 \mathrm{~cm}$ ). However, no significant difference was found in MTD between the SCS group and the PASCS group (Table 4). Serum potassium concentration was significantly greater in the SCS group than in the PASCS group (difference, $0.97 \mathrm{mEq} / \mathrm{L} ; 95 \% \mathrm{CI}, 0.38$ to $1.54 \mathrm{mEq} / \mathrm{L}$ ). However, no significant difference was found in serum potassium concentration between the PASCS group and the PA group (Table 4).

The cutoff value of $2.4 \mathrm{~cm}$ for tumor size seemed to produce the largest proportion of classified patients (91.0\%). Patients with PA who had a tumor size of $>2.4$ cm almost certainly had the elements of PASCS (specificity $100 \%)$. Namely, the sensitivity and specificity were calculated to be 58.0 and $100 \%$, respectively, when the cutoff point for tumor diameter was set to $2.4 \mathrm{~cm}$. The odds ratio for tumor diameter when comparing PA with PASCS was 0.06 (95\% CI, 0.006-0.261).

\section{Discussion}

We found several clinical and laboratory differences between patients with PASCS and patients with either PA or SCS. Regarding the impact of PA and SCS on glucose metabolism, the risk of developing DM in SCS is enhanced by the overproduction of cortisol that leads to increased gluconeogenesis [20]. Moreover, the risk is also enhanced by PA through 1) a hypokalemia-induced decrease in initial pancreatic insulin release and 2) a reduction in insulin sensitivity [21-23]. Hypokalemia is caused by the mineralocorticoid receptor-mediated overexcretion of potassium from the kidneys in both hypercortisolism and hyperaldosteronism [12, 24, 25]. Serum potassium concentration decreased significantly in the PA group than in the SCS group $(p<0.01)$. Similarly, the concurrence of PA and SCS significantly decreased serum potassium concentration against the SCS group $(p<0.01)$, but not the PA group. Of special note was the fact that the PASCS group involving both hyperaldosteronism and hypercortisolism did not show any greater decrease in serum potassium concentration as compared with the PA group. The mineralocorticoid receptors (MRs) bind both mineralocorticoids and glucocorticoids with high affinity (deoxycorticosterone = corticosterone $\geq$ aldosterone $=$ cortisol) [26]. On the other hand, a cortisol-degrading enzyme-11 $\beta$ -

Table 3 Blood steroid profiles of patients with PA or PASCS

\begin{tabular}{|c|c|c|c|}
\hline & PA $(n=45)$ & $\operatorname{PASCS}(n=14)$ & PA vs. PASCS \\
\hline & $\begin{array}{l}\text { Mean } \pm \text { SD } \\
\text { Median [IQR] }\end{array}$ & $\begin{array}{l}\text { Mean } \pm \text { SD } \\
\text { Median [IQR] }\end{array}$ & $P$ value \\
\hline $\mathrm{PAC}, \mathrm{pg} / \mathrm{mL}$ & 208.0 [273.0-159.8] & $255.0[713.3-153.5]$ & $<0.005$ \\
\hline PRA, ng/mL/h & $0.2[0.3-0.1]$ & $0.15[0.3-0.1]$ & NS \\
\hline PAC/PRA ratio & $1258.3[1956.3-643.1]$ & $1450.0[5010.0-529.4]$ & $<0.005$ \\
\hline PRA in the furosemide upright posture challenge test, $\mathrm{ng} / \mathrm{mL} / \mathrm{h}$ & $0.4[0.7-0.2]$ & $0.2[0.8-0.15]$ & NS \\
\hline PAC in the saline infusion test, $\mathrm{pg} / \mathrm{mL}$ & $160.0 \pm 166.5$ & $313.5 \pm 364.8$ & NS \\
\hline PAC/PRA ratio in the captopril challenge test & $730.7 \pm 745.7$ & $3028.5 \pm 3648.9$ & $<0.001$ \\
\hline PAC in the captopril challenge test, $\mathrm{pg} / \mathrm{mL}$ & $149.0 \pm 94.2$ & $348.6 \pm 340.1$ & $<0.005$ \\
\hline Cortisol, $\mu \mathrm{g} / \mathrm{dL}$ & $12.4 \pm 4.3$ & $16.4 \pm 6.6$ & $<0.05$ \\
\hline $\mathrm{ACTH}, \mathrm{pg} / \mathrm{mL}$ & $23.1 \pm 13.6$ & $18.2 \pm 18.8$ & NS \\
\hline DHEAS, $\mu \mathrm{g} / \mathrm{dL}$ & $111.5 \pm 75.1$ & $78.5 \pm 129.8$ & NS \\
\hline ACTH in the $\mathrm{CRH}$ challenge test, $\mathrm{pg} / \mathrm{mL}$ & $57.1 \pm 10.8$ & $18.9 \pm 8.9$ & $<0.005$ \\
\hline
\end{tabular}

Values are expressed as mean \pm SD in the upper row or median [IQR] in the lower row

$P A$ primary aldosteronism, $P A S C S$ primary aldosteronism plus subclinical Cushing's syndrome, $S D$ standard deviation, $I Q R$ interquartile range, $P A C$ plasma aldosterone concentration, $P R A$ plasma renin activity, NS not significant, $A C T H$ adrenocorticotropic hormone, DHEAS dehydroepiandrosterone sulfate, $C R H$ corticotropin-releasing hormone 
Table 4 Multiple regression analysis on maximum tumor diameter and serum potassium concentration with respect to patients in the PA, SCS, and PASCS groups who had a unilateral adrenal tumor $(n=65)$

\begin{tabular}{|c|c|c|c|c|c|c|}
\hline & \multicolumn{3}{|c|}{ Crude model } & \multicolumn{3}{|c|}{ Adjusted model $^{a}$} \\
\hline & Difference & $(95 \% \mathrm{Cl})$ & $P$ value & Difference & $(95 \% \mathrm{Cl})$ & $P$ value \\
\hline \multicolumn{7}{|l|}{ MTD, cm } \\
\hline $\operatorname{PASCS}\left(n=12^{\mathrm{b}}\right)$ & Reference & & & Reference & & \\
\hline $\mathrm{PA}\left(n=41^{\mathrm{C}}\right)$ & -1.24 & $(-1.70$ to -0.78$)$ & $<0.001$ & -1.19 & $(-1.66$ to -0.72$)$ & $<0.001$ \\
\hline $\operatorname{SCS}(n=12)$ & -0.04 & $(-0.58$ to 0.57$)$ & NS & -0.01 & $(-0.55$ to 0.54$)$ & NS \\
\hline \multicolumn{7}{|c|}{ Serum potassium concentration, $\mathrm{mEq} / \mathrm{L}$} \\
\hline $\operatorname{PASCS}\left(n=12^{b}\right)$ & Reference & & & Reference & & \\
\hline $\mathrm{PA}\left(\mathrm{n}=41^{\mathrm{C}}\right)$ & 0.23 & $(-0.23$ to 0.69$)$ & NS & 0.24 & $(-0.25$ to 0.72$)$ & NS \\
\hline $\operatorname{SCS}(n=12)$ & 0.96 & (0.38 to 1.53$)$ & $<0.005$ & 0.97 & (0.38 to 1.54$)$ & $<0.005$ \\
\hline
\end{tabular}

${ }^{a}$ Consists of 65 patients who had a unilateral adrenal tumor $(41,12$, and 12 patients with PA, SCS, and PASCS, respectively). All the models were adjusted for age, sex, and BMI at the time of diagnosis

${ }^{\mathrm{b}}$ The numbers of patients who remained after the exclusion of 2 patients who had bilateral tumors and who missed the maximum tumor diameter

'The numbers of patients who remained after the exclusion of the following patients who missed the maximum tumor diameter: 1 patient who had a unilateral adrenal tumor and 3 patients who had bilateral adrenal tumors

PA primary aldosteronism, SCS subclinical Cushing's syndrome, NS not significant, PASCS primary aldosteronism plus subclinical Cushing's syndrome, CI confidence interval, MTD maximum tumor diameter

hydroxysteroid dehydrogenase type 2 (11ß-HSD2)-is expressed in renal epithelial cells and regulates the binding of aldosterone to the MRs by impeding cortisol binding to the MRs through the inactivation of cortisol to cortisone [26, 27]. Namely, this physiological event explains the MR-mediated renal excretion of potassium that is enhanced by both cortisol and aldosterone. We hypothesize that the renal potassium excretion-enhancing activity is greater for aldosterone than for cortisol due to the $11 \beta$ HSD2-induced, extensive inactivation of cortisol and that the hyperaldosteronism-enhanced renal excretion of potassium in patients with PASCS becomes more apparent, with the less effect of hypercortisolism on renal potassium excretion. Zallocchi et al. [28] described that renal 11ß-HSD2 activity is regulated by glucocorticoids, is downregulated following adrenalectomy, and is restored by corticosterone replacement. These findings lead us to hypothesize that $11 \beta-H S D 2$ may suppress the binding of corticosteroids to the MRs almost completely in subclinical hypercortisolism or that the expression/activity of renal 11/-HSD2 may be increased in PA. However, these hypotheses require further research for its demonstration.

The proportion of DM patients increased significantly in the PASCS group than in the PA group $(p<0.05)$, which is in line with a previous study that described abnormal glucose metabolism in PA patients with cortisol hypersecretion [29]. Hyperaldosteronism found in patients with PA also induces abnormal glucose metabolism [21-23], although being less intense as compared with hypercortisolism found in patients with SCS. The proportions of DM patients in the PA and SCS groups increased, which resulted to nullify a statistically significant difference in the proportion of DM patients between the 2 study groups. The fact that the risk for DM is increased in PA patients with mild glucocorticoid excess has been reported [30-32]; the finding was also described in Japanese patients with PA and patients with PASCS [33].

Interestingly, patients with PASCS involving hypercortisolism- and hyperaldosteronism-induced hypokalemia showed neither additive or synergic impact on abnormal glucose metabolism contrary to our prediction. The proportion of DM patients was comparable between the PASCS group and the SCS group. However, the reason for these findings is unknown, awaiting the further accumulation of clinical evidence.

MTD was significantly smaller $(p<0.001)$ in the PA group than in the PASCS or SCS group, and multiple regression analysis on MTD revealed that MTD was significantly larger by $1.2 \mathrm{~cm}$ in the PASCS group than in the PA group $(p<0.001)$. Previous studies $[8,34]$ examined the clinical characteristics of patients with PA or PASCS and described significant differences in MTD between the 2 study groups. Their results were concordant with and support our results that indicated no significant difference in MTD between the PASCS group and the SCS group.

Most of previous clinical studies in patients with SCS have described adrenal tumors of $\geq 2 \mathrm{~cm}$ in diameter [35, 36]. In addition, an adrenal adenoma causing the overproduction of both cortisol and aldosterone is considered to have $\mathrm{a} \geq 2.5$ $\mathrm{cm}$ diameter [34]. In the present study, however, the adrenal tumor was smaller in both patients with SCS and patients with PASCS. Concretely, the smallest MTD was $1.1 \mathrm{~cm}$ in patients with PASCS (Fig. 1). None of patients, who had PA and an adrenal tumor $<1 \mathrm{~cm}$ in diameter, developed SCS. Therefore, the dexamethasone suppression test may not be required for them.

Regarding bone metabolism impairment in SCS, the risk of developing osteoporosis is enhanced by the overproduction of cortisol in SCS $[37,38]$. On the other 
hand, hyperaldosteronism is also known to increase the risk for osteoporosis [39]. SCS and PA are the risk factors for a reduction in BMD and an increase in vertebral fracture [37-39]. In the present study, serum ALP level was significantly greater in the PASCS group than in the PA group $(p<0.01)$. No significant difference was found in serum ALP level between the SCS group and the PASCS group. If this ALP represents bone alkaline phosphatase (BAP), the deleterious effects of hyperaldosteronism on bone metabolism might be masked by the severe abnormalities of bone metabolism caused by hypercortisolism in patients with PASCS. However, the relevant effects are difficult to assess by means of bone metabolism markers [eg, BAP] in patients with hypercortisolism as found in SCS [37]. Unfortunately, we neither used bone metabolism markers, nor measured BMD. Therefore, we will intend to investigate these variables in the future.

\section{Limitations}

The present study has several limitations. First, the study was retrospective in design and had a relatively small number of patients. Therefore, selection bias and sampling bias cannot be discarded. Second, not all patients underwent AVS or had a histopathological diagnosis. Patients, to whom challenge tests for either PA or SCS were conducted, were not included in the present study. Hence, the number of patients resulted to be relatively small. Third, the lack of data in the present study impeded the analysis of BMD and bone metabolism markers. Fourth, ${ }^{131}$ I-adosterol adrenal scintigraphy is not only useful for the diagnosis of SCS, but also is a very important imaging modality to predict postsurgical hypoadrenalism [40]. However, we could not investigate the latter.

\section{Conclusions}

We could not obtain any reference criteria to surely distinguish patients with concurrent endocrinopathies from those with a single endocrinopathy. However, clinicians should suspect the presence of concurrent SCS in patients with PA when detecting an adrenal tumor $(\geq 1 \mathrm{~cm}$ in diameter) on the CT scans.

\footnotetext{
Abbreviations

ACTH: Adrenocorticotropic hormone; ALP: Alkaline phosphatase; BMI: Body mass index; $\mathrm{CRH}$ : corticotropin-releasing hormone; CT: computed tomography; DBP: Diastolic blood pressure; DHEAS: Dehydroepiandrosterone sulfate; FPG: Fasting plasma glucose; HbA1c: Hemoglobin A1c; HDL-C: Highdensity lipoprotein cholesterol; HU: Hounsfield unit; LDL-C: Low-density lipoprotein cholesterol; MTD: Maximum tumor diameter; NGSP: National glycohemoglobin standardization program; PA: Primary aldosteronism; PAC: Plasma aldosterone concentration; PASCS: Primary aldosteronism plus subclinical Cushing's syndrome; PRA: Plasma renin activity; SBP: Systolic blood pressure; SCS: Subclinical Cushing's syndrome; TG: Triglyceride; UA: Uric acid
}

\section{Acknowledgments}

The authors would like to express their gratitude Kazuyuki Inoue, MD and Takujiro luchi, MD for their role in the data collection. The authors also thank Satoshi Sakima, MD, for valuable discussions about the manuscript.

\section{Authors' contributions}

SY analyzed and interpreted the data, drafted, and finalized the manuscript. YK performed statistical analyses, YH, YK, SI, YO, MI, II, AS, and MN

contributed to the discussion and critically revised the manuscript, AS and $\mathrm{MN}$ are taking full responsibility for the work as a whole. All authors read and approved the final manuscript.

\section{Funding}

No funding was obtained for this study.

\section{Availability of data and materials}

The datasets analyzed during the current study are available from the corresponding author on a reasonable request.

\section{Ethics approval and consent to participate}

All participants gave written informed consent. The present study followed the recommendations of the Declaration of Helsinki and was approved by the ethics committee of Saitama Medical University (18049.01).

\section{Consent for publication}

This manuscript does not report personal data such as individual details, images or videos; therefore, consent for publication is not applicable.

\section{Competing interests}

The authors declare that they have no conflict of interest.

\section{Author details}

'Department of Endocrinology and Diabetes, Saitama Medical University, Morohongo 38, Moroyama, Iruma-gun, Saitama 350-0495, Japan.

2Department of Home Care Medicine, Sowa Hospital, Sagamihara, Kanagawa, Japan. ${ }^{3}$ Department of Diabetes, Metabolism and Endocrinology, Ichikawa Hospital, International University of Health and Welfare, Chiba, Japan.

Received: 15 May 2019 Accepted: 8 January 2020

Published online: 13 January 2020

\section{References}

1. Mulatero P, Stowasser M, Loh KC, Fardella CE, Gordon RD, Mosso L, et al. Increased diagnosis of primary aldosteronism, including surgically correctable forms, in centers from five continents. J Clin Endocrinol Metab. 2004;89:1045-50.

2. Kageyama K, Oki Y, Sakihara S, Nigawara T, Terui K, Suda T. Evaluation of the diagnostic criteria for Cushing's disease in Japan. Endocr J. 2013;60:127-35.

3. Newell-Price J, Bertagna X, Grossman AB, Nieman LK. Cushing's syndrome. Lancet. 2006;367:1605-17.

4. Terzolo M, Pia A, Reimondo G. Subclinical Cushing's syndrome: definition and management. Clin Endocrinol. 2012;76:12-8.

5. lacobone M, Citton M, Scarpa M, Viel G, Boscaro M, Nitti D. Systematic review of surgical treatment of subclinical Cushing's syndrome. Br J Surg. 2015;102:318-30.

6. Fallo F, Bertello C, Tizzani D, Fassina A, Boulkroun S, Sonino N, et al. Concurrent primary aldosteronism and subclinical cortisol hypersecretion: a prospective study. J Hypertens. 2011;29:1773-7.

7. Piaditis GP, Kaltsas GA, Androulakis II, Gouli A, Makras P, Papadogias D, et al. High prevalence of autonomous cortisol and aldosterone secretion from adrenal adenomas. Clin Endocrinol. 2009;71:772-8.

8. Hiraishi K, Yoshimoto T, Tsuchiya K, Minami I, Doi M, Izumiyama H, et al. Clinicopathological features of primary aldosteronism associated with subclinical Cushing's syndrome. Endocr J. 2011;58:543-51.

9. Yanase T, Oki Y, Katabami T, Otsuki M, Kageyama K, Tanaka T, et al. New diagnostic criteria of adrenal subclinical Cushing's syndrome: opinion from the Japan Endocrine Society. Endocr J. 2018;65:383-93.

10. Lee SH, Song KH, Kim J, Park S, Ahn SH, Kim H, et al. New diagnostic criteria for subclinical hypercortisolism using postsurgical hypocortisolism: the cowork of adrenal research study. Clin Endocrinol. 2017;86:10-8. 
11. Nishikawa T, Omura M, Satoh F, Shibata H, Takahashi K, Tamura N, et al. Task force committee on primary Aldosteronism, the Japan Endocrine Society guidelines for the diagnosis and treatment of primary aldosteronism - the Japan Endocrine Society 2009. Endocr J. 2011:58:711-21.

12. Funder JW, Carey RM, Mantero F, Murad MH, Reincke M, Shibata H, et al. The management of primary aldosteronism: Case detection, diagnosis, and treatment: an Endocrine Society clinical practice guideline. J Clin Endocrinol Metab. 2016;101:1889-916.

13. Minami I, Yoshimoto T, Hirono Y, Izumiyama H, Doi M, Hirata Y. Diagnostic accuracy of adrenal venous sampling in comparison with other parameters in primary aldosteronism. Endocr J. 2008;55:839-46.

14. Ogihara T, Saruta T, Rakugi H, Fujimoto A, Ueshima K, Yasuno S, et al. CASE-J trial group, relationship between the achieved blood pressure and the incidence of cardiovascular events in Japanese hypertensive patients with complications: a sub-analysis of the CASE-J trial. Hypertens Res. 2009;32:248-54.

15. Committee of the Japan Diabetes Society on the Diagnostic Criteria of Diabetes Mellitus, Seino Y, Nanjo K, Tajima N, Kadowaki T, Kashiwagi A, Araki $E$, et al. Report of the committee on the classification and diagnostic criteria of diabetes mellitus. J Diabetes Investig. 2010;1:212-28.

16. Teramoto T, Sasaki J, Ueshima H, Egusa G, Kinoshita M, Shimamoto K, et al. Japan atherosclerosis society (JAS) Committee for Epidemiology and Clinical Management of atherosclerosis. Diagnostic criteria for dyslipidemia, executive summary of Japan atherosclerosis society (JAS) guideline for diagnosis and prevention of atherosclerotic cardiovascular diseases for Japanese. J Atheroscler Thromb. 2007;14:155-8.

17. Omura M, Saito J, Yamaguchi K, Kakuta Y, Nishikawa T. Prospective study on the prevalence of secondary hypertension among hypertensive patients visiting a general outpatient clinic in Japan. Hypertens Res. 2004;27:193-202.

18. Makita K, Nishimoto K, Kiriyama-Kitamoto K, Karashima S, Seki T, Yasuda M, et al. A novel method: super-selective adrenal venous sampling. J Vis Exp. 2017:127:55716.

19. Dekkers T, Deinum J, Schultzekool LJ, Blondin D, Vonend O, Hermus AR, et al. Plasma metanephrine for assessing the selectivity of adrenal venous sampling. Hypertension. 2013;62:1152-7.

20. Bancos I, Alahdab F, Crowley RK, Chortis V, Delivanis DA, Erickson D, et al. Therapy of endocrine disease: improvement of cardiovascular risk factors after adrenalectomy in patients with adrenal tumors and subclinical Cushing's syndrome: a systematic review and meta-analysis. Eur J Endocrinol. 2016;175:R283-95.

21. Corry DB, Tuck ML. The effect of aldosterone on glucose metabolism. Curr Hypertens Rep. 2003:5:106-9.

22. Remde H, Hanslik G, Rayes N, Quinkler M. Glucose metabolism in primary aldosteronism. Horm Metab Res. 2015:47:987-93.

23. Watanabe $D$, Yatabe M, Ichihara A. Evaluation of insulin sensitivity and secretion in primary aldosteronism. Clin Exp Hypertens. 2016;38:613-7.

24. Young WF. Primary aldosteronism: renaissance of a syndrome. Clin Endocrinol. 2007;66:607-18

25. Pivonello R, Isidori AM, De Martino MC, Newell-Price J, Biller BM, Colao A. Complications of Cushing's syndrome: state of the art. Lancet Diabetes Endocrinol. 2016:4:611-29.

26. Funder JW. Mineralocorticoid receptors: distribution and activation. Heart Fail Rev. 2005:10:15-22

27. Ferrari P, Sansonnens A, Dick B, Frey FJ. In vivo 11 beta-HSD-2 activity: variability, salt-sensitivity, and effect of licorice. Hypertension. 2001;38:1330-6.

28. Zallocchi ML, Matkovic L, Calvo JC, Damasco MC. Adrenal gland involvement in the regulation of renal 11 beta-hydroxysteroid dehydrogenase 2. J Cell Biochem. 2004;92:591-602.

29. Gerards J, Heinrich DA, Adolf C, Meisinger C, Rathmann W, Sturm L, et al. Impaired glucose metabolism in primary aldosteronism is associated with cortisol co-secretion. J Clin Endocrinol Metab. 2019. https://doi.org/10.1210/ jc.2019-00299 [Epub ahead of print]

30. Wu VC, Chueh SJ, Chen L, Chang CH, Hu YH, Lin YH, et al. Risk of new-onset diabetes mellitus in primary aldosteronism: a population study over 5 years. J Hypertens. 2017;35:1698-708.

31. Arlt W, Lang K, Sitch AJ, Dietz AS, Rhayem Y, Bancos I, et al. Steroid metabolome analysis reveals prevalent glucocorticoid excess in primary aldosteronism. JCl Insight. 2017;2:e93136.

32. Beuschlein F, Reincke M, Arlt W. The impact of Connshing's syndrome mild cortisol excess in primary aldosteronism drives diabetes risk. J Hypertens. 2017;35:2548.

33. Akehi $Y$, Yanase $T$, Motonaga $R$, Umakoshi $H$, Tsuiki M, Takeda $Y$, et al. High prevalence of diabetes in patients with primary aldosteronism (PA) associated with subclinical hypercortisolism and prediabetes more prevalent in bilateral than unilateral PA: a large, multicenter cohort study in Japan Diabetes Care. 2019;42:938-45.

34. Späth M, Korovkin S, Antke C, Anlauf M, Willenberg HS. Aldosterone- and cortisol-co-secreting adrenal tumors: the lost subtype of primary aldosteronism. Eur J Endocrinol. 2011;164:447-55.

35. Maehana T, Tanaka T, Itoh N, Masumori N, Tsukamoto T. Clinical outcomes of surgical treatment and longitudinal non-surgical observation of patients with subclinical Cushing's syndrome and nonfunctioning adrenocortical adenoma. Indian J Urol. 2012;28:179-83.

36. Rockall AG, Babar SA, Sohaib SA, Isidori AM, Diaz-Cano S, Monson JP, et al. CT and MR imaging of the adrenal glands in ACTH-independent Cushing syndrome. Radiographics. 2004:24:435-52

37. Chiodini I, Vainicher CE, Morelli V, Palmieri S, Cairoli E, Salcuni AS, et al. Mechanisms in endocrinology: endogenous subclinical hypercortisolism and bone: a clinical review. Eur J Endocrinol. 2016;175:R265-82.

38. Hardy RS, Zhou H, Seibel MJ, Cooper MS. Glucocorticoids and bone: consequences of endogenous and exogenous excess and replacement therapy. Endocr Rev. 2018;39:519-48.

39. Asbach $E$, Bekeran $M$, Reincke M. Parathyroid gland function in primary aldosteronism. Horm Metab Res. 2015;47:994-9.

40. Ricciato MP, Di Donna V, Perotti G, Pontecorvi A, Bellantone R, Corsello SM. The role of adrenal scintigraphy in the diagnosis of subclinical Cushing's syndrome and the prediction of post-surgical hypoadrenalism. World J Surg. 2014;38:1328-35.

\section{Publisher's Note}

Springer Nature remains neutral with regard to jurisdictional claims in published maps and institutional affiliations.
Ready to submit your research? Choose BMC and benefit from:

- fast, convenient online submission

- thorough peer review by experienced researchers in your field

- rapid publication on acceptance

- support for research data, including large and complex data types

- gold Open Access which fosters wider collaboration and increased citations

- maximum visibility for your research: over $100 \mathrm{M}$ website views per year

At BMC, research is always in progress.

Learn more biomedcentral.com/submissions 